\title{
Genetic Evaluation of Fertility Traits of Dairy Cattle Using a Multiple-Trait Animal Model
}

\author{
Z. Liu, ${ }^{1}$ J. Jaitner, F. Reinhardt, E. Pasman, S. Rensing, and R. Reents \\ Vereinigte Informationssysteme Tierhaltung w.V. (VIT), Heideweg 1, D-27283 Verden, Germany
}

\begin{abstract}
A genetic evaluation system was developed for 5 fertility traits of dairy cattle: interval from first to successful insemination and nonreturn rate to $56 \mathrm{~d}$ of heifers, and interval from calving to first insemination, nonreturn rate to $56 \mathrm{~d}$, and interval first to successful insemination of cows. Using the 2 interval traits of cows as components, breeding values for days open were derived. A multiple-trait animal model was applied to evaluate these fertility traits. Fertility traits of later lactations of cows were treated as repeated measurements. Genetic parameters were estimated by REML. Mixed model equations of the genetic evaluation model were solved with preconditioned conjugate gradients or the Gauss-Seidel algorithm and iteration on data techniques. Reliabilities of estimated breeding values were approximated with a multi-trait effective daughter contribution method. Daughter yield deviations and associated effective daughter contributions were calculated with a multiple trait approach. The genetic evaluation software was applied to the insemination data of dairy cattle breeds in Germany, Austria, and Luxembourg, and it was validated with various statistical methods. Genetic trends were validated. Small heritability estimates were obtained for all the fertility traits, ranging from $1 \%$ for nonreturn rate of heifers to $4 \%$ for interval calving to first insemination. Genetic and environmental correlations were low to moderate among the traits. Notably, unfavorable genetic trends were obtained in all the fertility traits. Moderate to high correlations were found between daughter yield-deviations and estimated breeding values (EBV) for Holstein bulls. Because of much lower heritabilities of the fertility traits, the correlations of daughter yield deviations with EBV were significantly lower than those from production traits and lower than the correlations from type traits and longevity. Fertility EBV were correlated unfavorably with EBV of milk production traits but favorably with udder health and
\end{abstract}

Received January 18, 2008.

Accepted July 10, 2008.

${ }^{1}$ Corresponding author: Zengting.Liu@vit.de longevity. Integrating fertility traits into a total merit selection index can halt or reverse the decline of fertility and improve the longevity of dairy cattle.

Key words: fertility, genetic evaluation, dairy cattle

\section{INTRODUCTION}

In recent decades, successful selection for milk production traits has led to a decline in female fertility in dairy cattle arising from an unfavorable, correlated selection response (Jorjani, 2006). To improve or at least slow the deterioration in fertility, more emphasis on fertility traits in selection is necessary (VanRaden et al., 2004; de Jong, 2005; Jamrozik et al., 2005Wall et al., 2005; van Doormaal et al., 2007). Germany has used a complete database to store all breeding data and has evaluated the first-service nonreturn rate for more than $10 \mathrm{yr}$. A routine genetic evaluation of female and male fertility has been applied to nonreturn rate through $90 \mathrm{~d}$ since the early 1980s. Because the single-trait genetic evaluation model does not consider some other useful fertility traits such as interval from calving to first insemination (CF) and interval from first to successful insemination (FS), a more up-to-date statistical model is required for accurately evaluating fertility of female and male animals.

Typically, national genetic evaluations included the following 5 fertility traits, 2 of them for heifers: nonreturn rate to $56 \mathrm{~d}(\mathbf{N R h})$, and interval from first to successful insemination (FSh), and 3 traits for cow fertility: $\mathrm{CF}$, nonreturn rate to $56 \mathrm{~d}$ (NRc), and interval from first to successful insemination (FSc). The 5 fertility traits fit well into the current Interbull grouping concept of fertility traits (Jorjani, 2006). As a combined trait, days open (DO) can be derived as the sum of CF and FSc (Jamrozik et al., 2005). The change in the definition of the nonreturn rate from 90 to $56 \mathrm{~d}$ was made for international harmonization of fertility traits.

A total of 17 countries or populations participated in Interbull's September 2007 test run of multiple across-country evaluation (MACE) for fertility traits; 16 of those countries were included in the Holstein run. Three of the Holstein populations had only binary traits (e.g., conception rate), 5 countries only interval 
Table 1. Descriptive statistics of the fertility data for January 2008 routine evaluation

\begin{tabular}{lcccccc}
\hline & $\begin{array}{c}\text { Insemination } \\
\text { records }\end{array}$ & $\begin{array}{c}\text { Females } \\
\text { with data }\end{array}$ & Cows with data & $\begin{array}{c}\text { Animals in } \\
\text { pedigree }\end{array}$ & $\begin{array}{c}\text { Herd-year } \\
\text { classes }\end{array}$ & $\begin{array}{c}\text { Total no. of } \\
\text { equations }\end{array}$ \\
\hline No. of levels & $25,526,858$ & $11,461,212$ & $8,788,810$ & $16,525,323$ & 522,030 & 37,198 \\
\hline
\end{tabular}

traits (e.g., calving interval, CI), and the remaining 8 countries had both types of fertility traits. Compared with the other trait groups, the fertility trait complex was considerably more heterogeneous in trait definition across countries, which complicated the current Interbull evaluations that are based on a single-trait MACE model. To make possible comparisons with all countries, both rate and interval fertility traits need to be considered in national genetic evaluation. The objective of this study was to develop a genetic evaluation system with a multiple trait animal model for the selected fertility traits.

\section{MATERIALS AND METHODS}

\section{Data for Genetic Evaluation}

Insemination records of heifers and cows from first to sixth lactations were chosen for the fertility genetic evaluation. Early, less-complete data were excluded by imposing the conditions that heifers must have been born from 1994 onward and calving years of cows must have been 1995 or later. Female animals from all farms enrolled in milk recording programs were considered in the genetic evaluation, including those not in a herdbook system. Insemination data of both AI bulls and natural service bulls were analyzed together.

Values of the fertility traits were required to be in pre-defined ranges. Insemination records were verified by calving information of the following lactation, if available. The fertility trait FS was only considered if it was verified by a subsequent calving. For calving to first insemination (CF), all insemination records with values from 21 through $250 \mathrm{~d}$ were used. From a given cut-off date for genetic evaluation, a time opportunity period of $100 \mathrm{~d}$ was considered to determine 56 -d nonreturn rate. The minimum value of FS was allowed to be $0 \mathrm{~d}$ unless more than one insemination record was available, in which case it was $11 \mathrm{~d}$. The smallest DO value was set to $21 \mathrm{~d}$. Maximum values for FS and DO were indirectly determined by using valid ranges of gestation length and calving interval, which were from 265 to $295 \mathrm{~d}$ for gestation length and from 286 and $600 \mathrm{~d}$ for calving interval. If the NR rate of a herd-year class was not significantly different from 1 (i.e., only successful inseminations were recorded), fertility data from that herd-year were discarded. This data check procedure was done separately for heifers and cows. The data exclusion was expected to reduce the impact of the noninformative fertility data on EBV. Details about further data editing procedures can be found in the article by Pasman et al. (2006).

Table 1 has a summary of the fertility data used for January 2008 joint evaluation for dairy cattle breeds Holstein, Red dairy cattle, and Jersey from Germany, Austria, and Luxembourg. The genetic evaluation was conducted jointly for 3 breeds and across 3 countries. A total of 25.5 million insemination records of 11.5 million heifers and cows were evaluated. The total number of equations amounted to over 111 million.

\section{Models and Methods for Genetic Evaluation}

Statistical Models for Genetic Evaluation. The fertility traits were analyzed with a multiple trait animal model, where all fixed effects are denoted in uppercase and random effects in lowercase:

$$
\begin{aligned}
\mathrm{y}_{i j k l m n o} & =\mathrm{H}_{i}+\mathrm{L}_{j}+\mathrm{B}_{o}+\mathrm{F}_{m}+\mathrm{t}_{m n} \\
& +a_{k}+\mathrm{p}_{k}+e_{i j k l m n o},
\end{aligned}
$$

where $\mathrm{y}_{\text {ijklmno }}$ denotes a fertility trait in the lth lactation $(l=0,1, \ldots, 6)$ of female animal $k, \mathrm{H}_{i}$ is fixed effect of the $i$ th herd-year, $\mathrm{L}_{j}$ is the $j$ th lactation group (heifer and 6 cow lactations) $\times$ age class (3 classes for heifers, 5 for the first 3 lactations, and 1 for the remaining lactations) $\times$ season (3 classes: January to March, April to August, and September to December) and year of insemination $\times$ region (eastern Germany and the rest). For heifers there were 3 age classes: $\leq 16,>16$ to 19 , and $>19 \mathrm{mo}$; for cows of the first 3 lactations, there were 5 classes each: $\leq 25,>25$ to $28,>28$ to $31,>31$ to 35 , and $>35$ mo for first-lactation cows, $\leq 36,>36$ to $40,>40$ to $44,>44$ to 48 , and $>48$ mo for second-lactation cows, and $\leq 50,51$ to $54,>54$ to $58,>58$ to 62 , and $>62$ mo for third-lactation cows, and there was just one class for lactation number $>3 ; \mathrm{B}_{o}$ is the oth effect of type of bull as service sire (proven sire or otherwise) $\times$ AI stud of service sire $\times$ AI stud servicing the female animal, $\mathrm{F}_{m}$ represents fixed effect of service sire $m, t_{m n}$ represents random effect of insemination year class $n$ within the service sire $m, \mathrm{a}_{k}$ is additive genetic effect of female $k$, $\mathrm{p}_{k}$ is random permanent environmental effect of female 
$k$, and $\mathrm{e}_{i j k l m n o}$ is the residual effect for this insemination record of the lactation.

Not all of the fertility traits were modeled with all the effects in the full model 1. For the interval trait of heifer FSh, only $\mathrm{H}_{i}, \mathrm{~L}_{j}$, and $\mathrm{a}_{k}$ were considered:

$$
\mathrm{FSh}_{i j k}=\mathrm{H}_{i}+\mathrm{L}_{j}+a_{k}+e_{i j k} \text {. }
$$

The sub-model for NRh of heifers contained $\mathrm{B}_{o}, \mathrm{~F}_{m}$, $t_{m n}$ plus the effects of FSh:

$$
\begin{gathered}
\mathrm{NRh}_{i j k m n o}=\mathrm{H}_{i}+\mathrm{L}_{j}+\mathrm{B}_{o}+\mathrm{F}_{m} \\
+\mathrm{t}_{m n}+a_{k}+e_{i j k m n o} .
\end{gathered}
$$

In comparison to NRh, NRc was evaluated with the additional random permanent environmental effect $\mathrm{p}_{k}$, and its evaluation model is model 1 . The 2 interval traits for cow fertility, $\mathrm{CF}$ and FSc, were analyzed with a sub-model including $\mathrm{H}_{i}, \mathrm{~L}_{j}, \mathrm{a}_{k}$, and $\mathrm{p}_{k}$ :

$$
\mathrm{CF}_{i j k l}, \mathrm{FSc}_{i j k l}=\mathrm{H}_{i}+\mathrm{L}_{j}+a_{k}+\mathrm{p}_{k}+e_{i j k l} \text {. }
$$

In matrix notation, the general model 1 can be written as:

$$
\mathbf{y}=\mathbf{X}_{h} \mathbf{h}+\mathbf{X}_{l} \mathbf{l}+\mathbf{X}_{b} \mathbf{b}+\mathbf{X}_{f} \mathbf{f}+\mathbf{Z}_{t} \mathbf{t}+\mathbf{Z} \mathbf{a}+\mathbf{Z} \mathbf{p}+\mathbf{e}
$$

where $\mathbf{y}$ is a vector of all observations, $\mathbf{h}$ is a vector of fixed herd-year effects $\left(\mathrm{H}_{i}\right.$ in model 1$), \mathbf{l}$ is a vector of fixed effects of lactation $\times$ age $\times$ season $\times$ year $\times$ region of inseminations ( $\mathrm{L}_{j}$ in model 1$), \mathbf{b}$ is a vector of fixed effects related to service sire grouping $\left(\mathrm{B}_{o}\right.$ in model 1$)$, $\mathbf{f}$ is a vector of fixed effects of service sire $\left(\mathrm{F}_{m}\right.$ in model $1), \mathbf{t}$ is a vector of random effects of within-sire years $\left(\mathrm{t}_{m n}\right.$ in model 1$)$, $\mathbf{a}$ is a vector of random additive genetic effects $\left(a_{k}\right), \mathbf{p}$ is a vector of permanent environmental effects ( $p_{k}$ in model 1 ), and $\mathbf{e}$ is a vector of residuals. The incidence matrices $\mathbf{X}_{h}, \mathbf{X}_{l}, \mathbf{X}_{b}, \mathbf{X}_{f}, \mathbf{Z}_{t}$, and $\mathbf{Z}$ correspond to the effects $\mathbf{h}, \mathbf{l}, \mathbf{b}, \mathbf{f}, \mathbf{t}, \mathbf{a}$, or $\mathbf{p}$. For residual effects $\operatorname{var}(\mathbf{e})=\mathbf{R}_{0} \otimes \mathbf{I}$, where $\mathbf{R}_{0}$ is the error (co) variance matrix $(5 \times 5)$, $\mathbf{I}$ is the identity matrix, and $\otimes$ is direct product operator. We assume that residual correlation between any pair of the 5 traits is null, except between the 2 heifer traits FSh and NRh being -0.49 . Permanent environmental effects were correlated among the 3 cow traits, and $\operatorname{var}(\mathbf{p})=\mathbf{P}_{0} \otimes \mathbf{I}$, where $\mathbf{P}_{0}$ is a $3 \times 3$ matrix. For additive genetic effects $\operatorname{var}(\mathbf{a})=\mathbf{G}_{0} \otimes \mathbf{A}$, where $\mathbf{G}_{0}$ is the genetic (co)variance matrix $(5 \times 5)$, and $\mathbf{A}$ is the relationship matrix among animals. We assume, as usual, that the random effects $\mathbf{p}$ and $\mathbf{e}$ are independently distributed among animals, and the relationship matrix accounts for correlations of the additive genetic effects among animals.

In contrast to the single-trait model previously used in Germany (Pasman et al., 2006), the paternal genetic effect of service sire is no longer included in the new genetic evaluation model. However, male fertility is still made available as $\mathrm{F}_{m}+\mathrm{t}_{m n}$, although it is expressed only at the phenotypic level. The within-service-sire year effects, $t_{m n}$, were assumed to follow the first-order autoregressive process, AR(1) (Wade and Quaas, 1993). The covariance matrix of the year effects was assumed to be $\operatorname{var}\left(\mathbf{t}_{m}\right)=\mathbf{T}_{0}$ for service sire $m$. For progenytested bulls or natural service bulls, only 1 year class was specified; but there were 4 year classes defined for proven bulls. In routine genetic evaluations, the current insemination year of a proven sire is defined as the origin of this $\mathrm{AR}(1)$ process, and the last year class combines the fourth insemination year and all previous years. Therefore, matrix $\mathbf{T}_{0}$ has a maximum dimension of $5 \times 5$. It was assumed that there was no correlation between the progeny testing period and the time of second crop. For every proven sire, a matrix containing variance and autocorrelation of within-bull year effects is set up and inverted using the algorithm by Wade and Quaas (1993), which allows unequal spacing or missing years. The maximum number of year classes is set to 4 , but more than 4 years may be included in analyses as a result of possible missing years.

Although threshold models or other nonlinear models are more appropriate for modeling the binary nonreturn rate, their high computational requirement prohibit their application in routine genetic evaluations of a large dairy cattle population such as German Holsteins. Therefore, we decided to apply the above linear model to the 2 binary traits for our large-scale genetic evaluation. To our knowledge, no research has been conducted to investigate the model difference for the 2 binary traits in large-scale genetic evaluations.

Solving the Mixed Model Equations. The mixed model equation system of the multiple-trait model 1 was solved with preconditioned conjugate gradients method (PCG; Lidauer et al., 1999; Ducrocq and Druet, 2003) or a Gauss-Seidel algorithm together with the iteration on data technique. As preconditioner, block diagonals were chosen for all the random effects and scalar diagonals for all the fixed effects. Solutions of all effects from a previous evaluation were used as starting values for current genetic evaluations. Phantom parents were grouped based on country of origin, 4 selection paths and birth year of animal; and the phantom parent groups were merged using a predefined 
minimum number of animals per group. Trait values were scaled to a similar variance to make genetic evaluations numerically more stable and (co)variance parameters were scaled accordingly in the iteration program. Because PCG and Gauss-Seidel algorithms gave practically identical solutions after 1,500 rounds of iteration for the data shown in Table 1, the solutions from Gauss-Seidel run were taken as official values. About 5.1 gigabytes of RAM was required for solving the equations, and the CPU was about $55 \mathrm{~s}$ per round of iteration on a single central processing unit of a 64bit Advanced Micro Devices Opteron Linux server.

Approximating Reliabilities and Calculating Daughter Yield Deviations. The multi-trait effective daughter contribution method (MTEDC; Liu et al., 2004) was applied to approximate reliability values of EBV of all the fertility traits, including the derived, combined trait DO and fertility indices. Using the method developed for test-day models (Liu et al., 2004), average yield deviations (AYD) of female animals and daughter yield deviations (DYD) of bulls were computed together with their associated effective daughter contribution (EDC). Two sets of EDC were made available for both single-trait and multiple-trait MACE (Jorjani, 2006). Either AYD of female animals or DYD of bulls can be utilized, together with their associated EDC, for further genetic analyses, such as marker-assisted genetic evaluation (Szyda et al., 2005) or setting up total merit indices with an approximate multiple-trait animal model (Tarrés et al., 2007).

\section{Models and Methods for Parameter Estimation}

Insemination records from 1999 to 2005 were selected for parameter estimation. Only Black-and-White and Red-and-White Holstein female animals were considered. Ancestors were traced back using the complete pedigree containing about 58 million animals. A multiple-trait sire model was used for analyzing a selected data set. As a control, a single-trait animal model, model 1, was fitted to a considerably smaller subset of the data. We intended to determine if the sire model resulted in significantly lower heritability estimates than the animal model. Because fertility data are, by nature, highly selected (i.e., only cows that were fertile in the previous lactation can have insemination records in current lactation), sequential data selection steps were carefully performed. On the trait level, only fertility traits with valid trait values were selected. On the lactation level, only sequential missing trait patterns in the order of CF, NRc, and FSc, were allowed. On the animal level, a female was included in the parameter estimation only if she had an insemination record as heifer.
To reduce computing requirements, herd-year classes were required to have at least 5 heifers or 10 cows. Each service sire was required to have a minimum number of 100 insemination records. A sire of females was included only if he had at least 50 daughters with fertility records. After these sequential selection procedures were imposed, 215,509 heifer and 282,183 cow insemination records remained for final parameter estimation with the sire model. In total, 2,437 bulls were evaluated. A total of 4,738 animals were included in the final pedigree file for parameter estimation. For the analyses with the animal model, a much smaller number of insemination records from a much larger number of females was used, and $30 \%$ of herds were randomly chosen. Male ancestors were traced back to birth year of 1980, and female ancestors were traced to 1995. This was in contrast to the sire model analyses in which all possible ancestors were considered. The animal model was applied only to single-trait analyses because of computing restraints.

A REML method was used to estimate the (co)variance components using software package VCE 5 (Kovač et al., 2002). Several bivariate analyses were conducted to use as much data and pedigree information as possible, because the 5 -trait analysis using the full data set was computationally infeasible. The (co)variance estimates from the sub-analyses were averaged to obtain the final parameter estimates. The difference in heritability estimates between the sire and animal models was not significant. Therefore, parameter estimates from the sire model were chosen when estimates of both models were available.

\section{RESULTS AND DISCUSSION}

\section{Selection of Fertility Traits for Routine Evaluation}

In the previous German genetic evaluation system, paternal genetic effect of service sire was fitted as a correlated trait to maternal genetic effect for the nonreturn rate to $90 \mathrm{~d}$. Because a very low heritability estimate was obtained in the parameter estimation for the paternal genetic effect, 0.002 , it was decided to remove this effect from the new fertility model for the NR traits. The decision to drop this correlated paternal genetic effect also agreed with the international harmonization of fertility traits (Jorjani, 2006). Paternal effects on NR are still included in the new model as the fixed effect of service sire. In the initial phase of this project, DO and CI were chosen as evaluated traits within the multi-trait model. It was found that the EBV of DO or CI had much greater variation than a test run with a single-trait model. The greater EBV variances were mainly caused by the fact that the data 
information of $\mathrm{CF}$ or FSc were double counted in the evaluation model, because $\mathrm{CF}$ and FSc are parts of DO and CI. Based on this finding, it was decided to include the component fertility traits $\mathrm{CF}$ and FSc in genetic evaluation and to subsequently derive EBV for DO as sum of the EBV of CF and FSc (Jamrozik et al., 2005).

\section{Estimates of Genetic Parameters}

Estimates of genetic parameters are in Table 2. All of the fertility traits had low heritability estimates ranging from 1 to $4 \%$. The heritability estimate of the interval trait $\mathrm{CF}$ was found to be almost 3 times as high as for the cow's conception traits NRc and FSc. Heritability estimates of the conception traits were similar for heifers and cows. Genetic and residual correlation estimates between both heifer traits were moderately negative. Genetic correlation estimate was moderately high between heifers and cows for the same trait NR (0.63) or FS (0.48). Genetic correlation between NRc and FSc was -0.39 , indicating the limited accuracy of using NR56 for projecting conception. The NR56 traits and $\mathrm{CF}$ were found to have very low genetic correlations. Because NRc is significantly less correlated with DO than the interval trait $\mathrm{FSc}$, the prediction of DO using NRc was less accurate than using CF. Among the cow fertility traits, both genetic and permanent environmental effects were correlated in similar magnitude and in the same direction. The 2 cow traits NRc and FSc had a low percentage of permanent environmental variance, in contrast to the fertility trait $\mathrm{CF}$, with $11 \%$ of phenotypic variance attributed to the permanent environmental effect. Despite the very low heritability estimates, the fertility traits had reasonably large genetic standard deviations (e.g., $9.8 \mathrm{~d}$ for DO) because of large phenotypic variation in the dairy cattle population. Approximate standard errors for the heritability estimates were from 0.11 to $0.24 \%$. The standard errors of the genetic correlation estimates ranged from 0.015 to 0.035 , and a similar range of standard errors were also found for the correlation estimates of permanent environment effects and the heifer residual correlation.

The parameter estimates fell within the range of estimates found in literature from various populations (Fogh et al., 2003; VanRaden et al., 2004; Jamrozik et al., 2005; Wall et al., 2005; Berry et al., 2007; Gredler et al., 2007). But the heritability estimates were smaller than those found in Canada (Jamrozik et al., 2005). In fact, the Canadian heritability estimates represented the upper bound of these parameter estimates. Similar heritability as well as genetic correlation estimates were also found in Nordic countries (Fogh et al., 2003). For the NR traits, the auto-correlation parameter

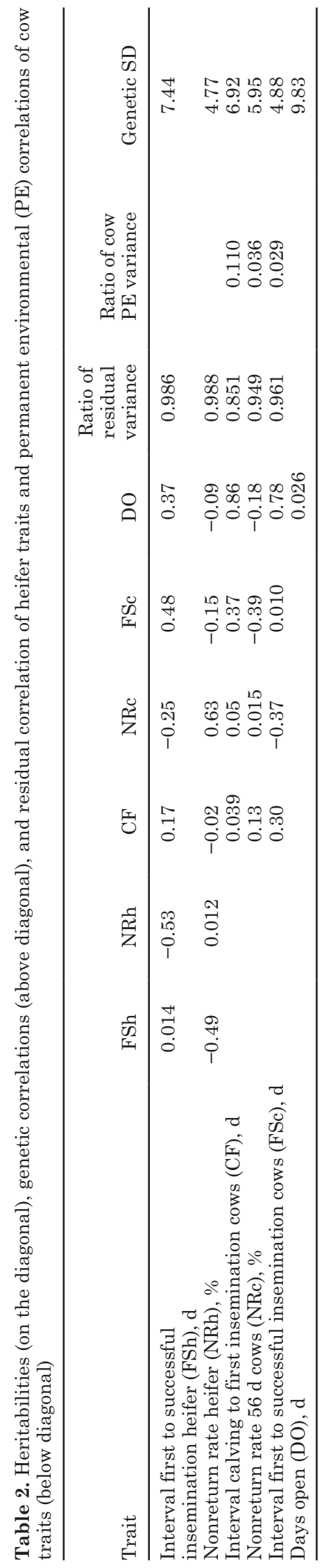

Journal of Dairy Science Vol. 91 No. 11, 2008 

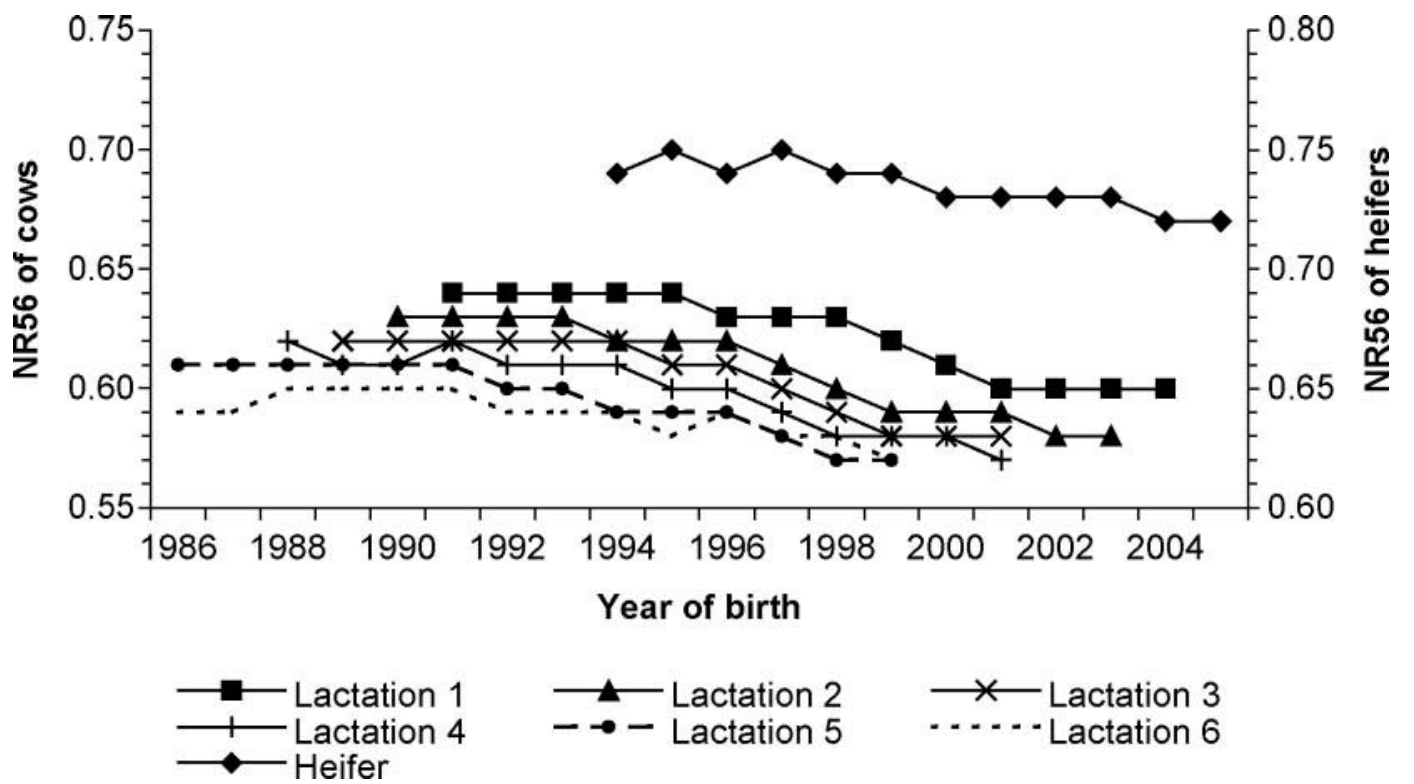

Figure 1. Phenotypic trend of nonreturn rate $56 \mathrm{~d}$ (NR56) in German Holsteins.

used in the genetic evaluation was 0.8 and variance of within-service-sire year effects was $1 \%$ of phenotypic variance. A comparison with the parameter estimates from other studies was not possible as no such estimates were available in literature.

\section{Genetic Evaluation Results}

Phenotypic and Genetic Trends. Phenotypic trends of the 5 fertility traits were studied using 25.2 million insemination records of Holstein females. Cow insemination records with $\mathrm{CF}$ only were not used for calculating the trends, because such records tend to have shorter $\mathrm{CF}$ than insemination records of more complete lactations at the time of data extraction for the genetic evaluation. The interval first to successful insemination FS was set to missing if no following calving was available. Figure 1 has phenotypic averages of NR traits in heifers and the first 6 lactations of cows. The NR decreased as lactation number increased, with the greatest difference of 0.05 between heifers and lactation 6 cows. Heifers have significantly greater NR than cows. For either heifers or cows, negative, unfavorable trends could be observed in the last $10 \mathrm{yr}$, although the unfavorable trends were weaker for heifers than for cows. It can be seen in Figure 2 that FS increased significantly in the 1990s, but the phenotypic trends have become flatter or even slightly reversed since then. As for NR traits, greater lactation numbers had longer FS interval, and heifers had much shorter FS than cows, with an average difference of $12.7 \mathrm{~d}$ between heifers and lactation- 6 cows. Similar phenotypic trends can be seen for CF in Figure 3 as for FS in Figure 2. From Figure 2, the interval first to successful insemination FS increased over time. In recent years, there was a slight drop in phenotypic trend in FS caused by the fact that cows or heifers that had shorter, complete records of FS entered into genetic evaluations earlier at the time of data extraction than females with longer FS. The trait CF had unfavorable phenotypic trends in 1990s, but the trends have become much flatter in recent years. Because of incomplete insemination records during the last year for respective lactations, $\mathrm{CF}$ average dropped dramatically in the last year; therefore, the drop in the CF phenotypic trend should be interpreted as arising from data selection. In all 3 figures, there was a different pattern in phenotypic trends of first lactation of cow fertility traits than all later lactations. Overall, a clear deterioration of all the fertility traits in German Holstein population was noted, although the unfavorable phenotypic trends have become less severe for CF and FSc in recent years.

Estimates of the nongenetic effects of model 1 were validated using available information. For instance, estimates of the average service sire effect $\mathrm{F}_{m}$ were compared with phenotypic means of mates of bulls, and both were found to be highly correlated. Variance of the estimated permanent environmental effect $\mathrm{p}_{k}$ was highly correlated with the number of insemination records per cow.

Figures 4 and 5 have estimated genetic trends of the fertility traits in Holstein AI bulls and Holstein female animals, respectively. The bulls were required to have at least 50 daughters in CF or the heifer trait 


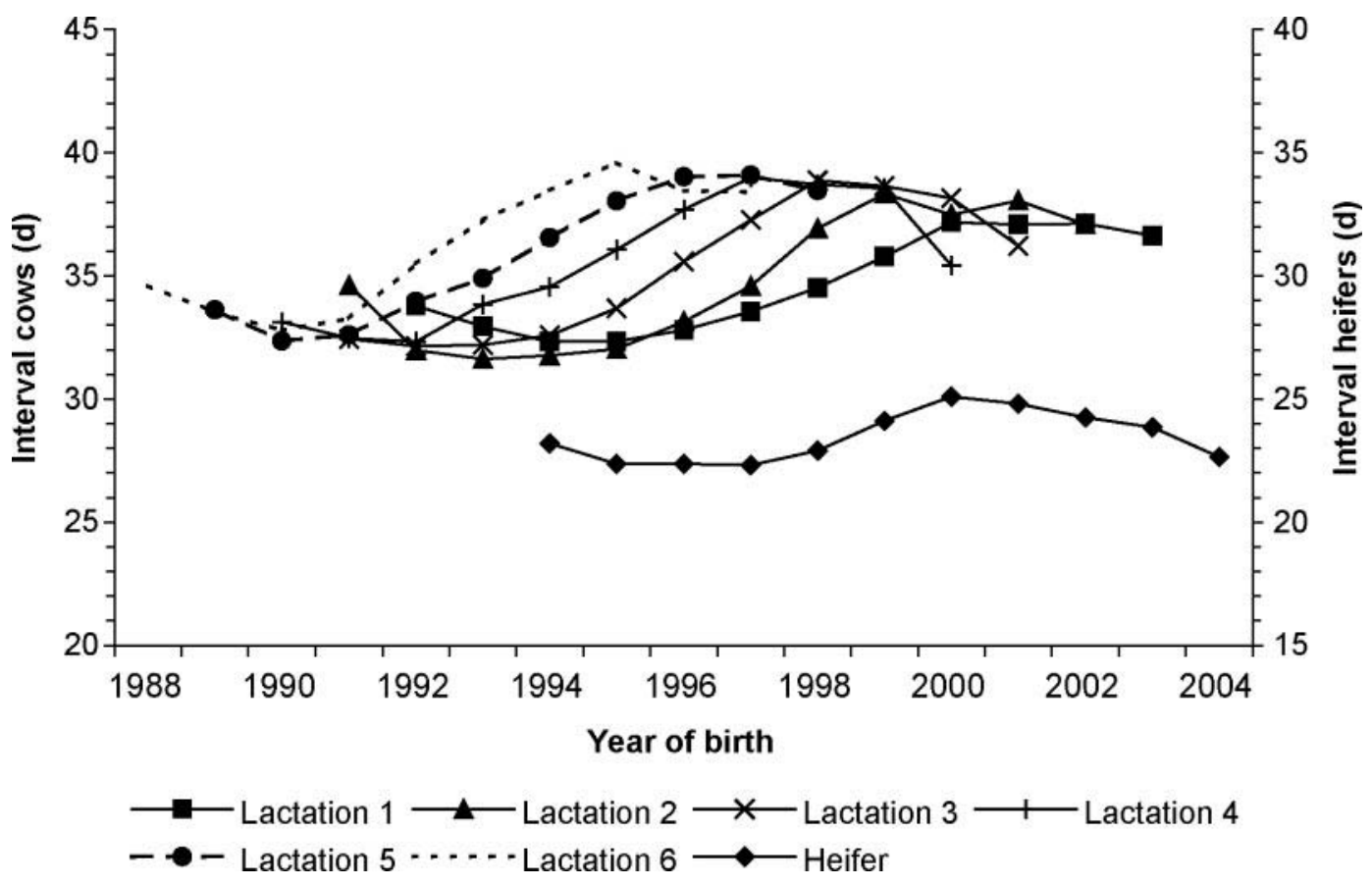

Figure 2. Phenotypic trend of interval from first to successful insemination in German Holsteins.

$\mathrm{NRh}$. All the female animals had heifer records as well as at least one cow insemination record. There were approximately 1,000 bulls or 800,000 female animals in each of the years plotted in either figure. It can be clearly seen that unfavorable genetic trends existed in
Holstein bulls and female animals for all the fertility traits. Because of the larger number of animals in each year, the genetic trends in the Holstein females were much smoother than those of the Holstein bulls. The less smooth genetic trends in Holstein bulls can be ex-

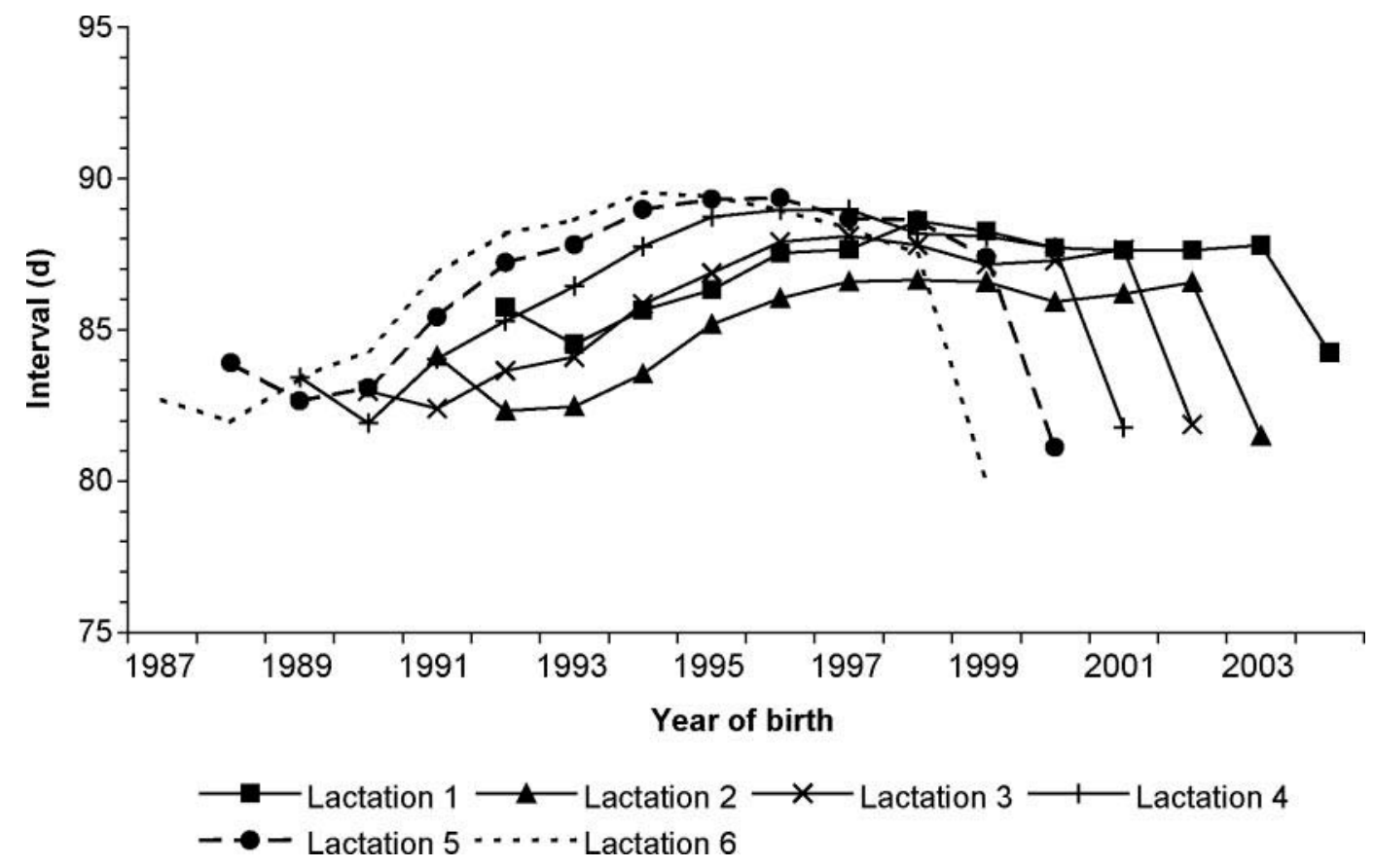

Figure 3. Phenotypic trend of interval from calving to first insemination in German Holstein cows. 

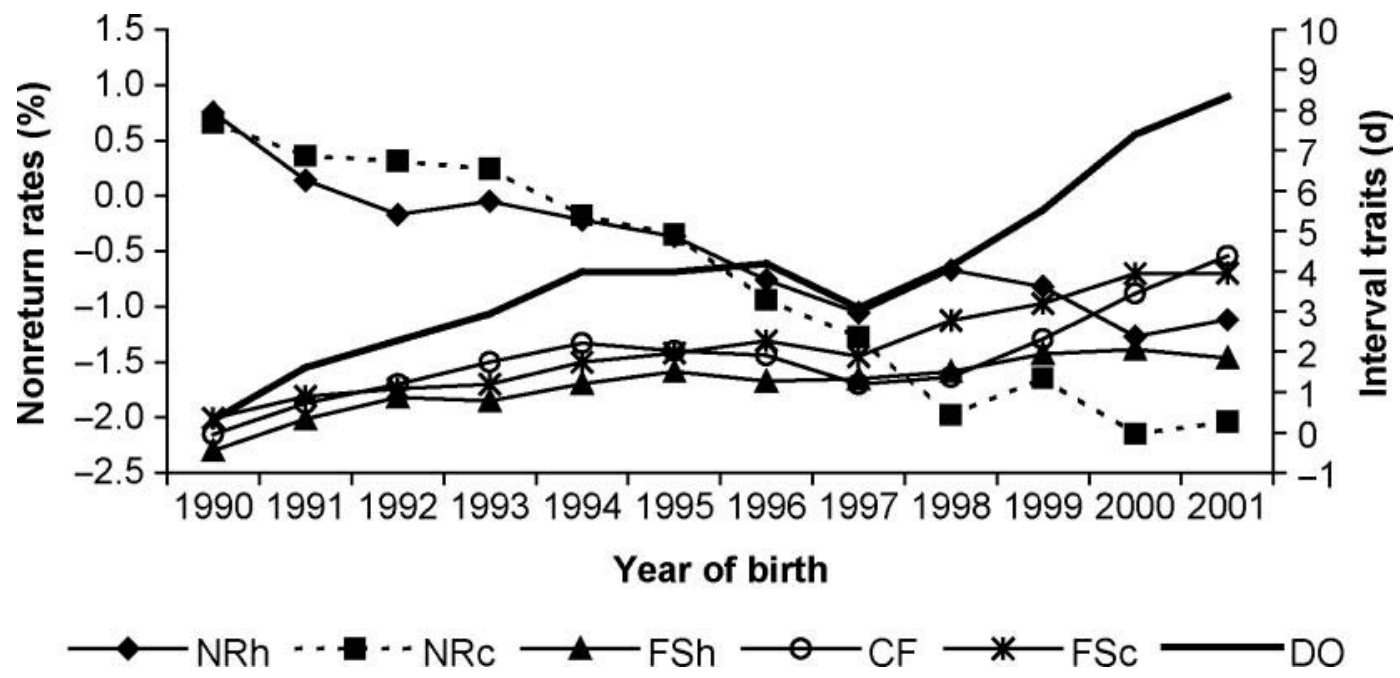

Figure 4. Genetic trends of heifer and cow fertility traits in German Holstein bulls with at least 50 daughters. NRh and NRc $=$ nonreturn rate of heifer and cow, respectively; FSh and FSc = interval first to successful insemination of heifer and cow, respectively; $\mathrm{CF}=$ interval calving to first insemination; and $\mathrm{DO}=$ days open.

plained by the fact that even a single popular bull sire with extreme fertility EBV could make the average EBV of bulls born in a particular year deviate much from the normal trends. Compared with the female animals, the Holstein AI bulls had much stronger, unfavorable trends in the fertility traits. For the same trait FS or NR, the cow fertility trait had a stronger trend than the heifer trait, mainly caused by very little culling imposed on heifers. Between birth year 1990 and 2001 for the German Holstein bulls or between 1994 and 2005 for German Holstein female animals, there was an increase of about 8.0 or $4.6 \mathrm{~d}$ of $\mathrm{DO}$, respectively, being equivalent to 81 or $47 \%$ of genetic standard deviations. In the same period, cow NRc EBV dropped 2.7\% (45\% genetic standard deviations) in the Holstein bulls and $2.5 \%$ in the Holstein females. The interval from first to successful insemination FSc increased by $3.6 \mathrm{~d}$ (74\% genetic standard deviations) in the Holstein bulls and $3.0 \mathrm{~d}$ in the Holstein females in the 12-yr period. For the fertility trait $\mathrm{CF}$, a similar and unfavorable genetic trend was found to be $4.4 \mathrm{~d}$ ( $64 \%$ genetic standard deviations) in the bulls and $1.6 \mathrm{~d}$ in the female animals during the same period. In summary, notably strong, unfavorable genetic trends were observed in both bulls and female animals for all the fertility traits. This fact may be explained by significant genetic progress achieved in production traits in the last decades.

$\boldsymbol{E B V}$ and $\boldsymbol{D Y D}$. Table 3 has correlations between DYD and EBV of Holstein bulls for the 5 fertility traits. In general, the correlation between DYD and EBV is much lower than for production traits (Liu et al., 2004) or longevity and type traits (Tarrés et al., 2007a), because the fertility traits have smaller heritabilities.
Among the 5 fertility traits, $\mathrm{CF}$ had the greatest correlations because of its greatest heritability value and the amount of contributing data. The 2 heifer traits had smaller correlations than the 3 cow fertility traits because of the difference in number of insemination records. It can be seen, as expected, that the correlations increase with the number of daughters. The fertility DYD values were associated with much lower reliability values than those for production traits (Liu et al., 2004), which means that the variance of DYD has a greater percentage of residual variance component. When a bull has at least 500 daughters with fertility traits, correlation of his DYD and EBV can reach 0.95 for both heifer traits and at least 0.98 for cow fertility traits. With the consideration of rather low reliability or EDC associated with the fertility DYD, a reasonably high consistency between DYD and EBV is shown in Table 3.

Similar to Table 3, Table 4 has correlations between DYD and EBV for Holstein bulls stratified by birth year. Only Black-and-White Holstein bulls with at least 50 daughters in each respective trait were chosen for this analysis. Because of the left truncation of fertility data for the routine genetic evaluation, there are fewer bulls having DYD in the early birth years. For the 3 cow fertility traits with up to 6 lactations, the youngest bulls born in 2002 and 2003 have significantly lower correlations between DYD and EBV than older bulls that tended to have more complete daughter information.

EBV Correlations with Other Traits. Based on the EBV of Black-and-White Holstein bulls with at least 50 daughters with respective fertility traits, all 
Table 3. Correlation of female fertility daughter yield deviations with EBV by number of daughters for Black-and-White Holstein bulls that had at least 10 daughters for respective traits in a January 2008 genetic evaluation

\begin{tabular}{|c|c|c|c|c|c|c|c|c|c|c|}
\hline $\begin{array}{l}\text { Daughters, } \\
\mathrm{n}\end{array}$ & \multicolumn{2}{|c|}{ Nonreturn rate heifer } & \multicolumn{2}{|c|}{$\begin{array}{l}\text { Interval first } \\
\text { to successful } \\
\text { service heifer }\end{array}$} & \multicolumn{2}{|c|}{$\begin{array}{l}\text { Interval calving to } \\
\text { first insemination }\end{array}$} & \multicolumn{2}{|c|}{ Nonreturn rate cow } & \multicolumn{2}{|c|}{$\begin{array}{l}\text { Interval first } \\
\text { to successful } \\
\text { service cow }\end{array}$} \\
\hline $10-19$ & 336 & 0.29 & 374 & 0.16 & 372 & 0.60 & 361 & 0.41 & 353 & 0.33 \\
\hline $20-29$ & 260 & 0.46 & 417 & 0.36 & 212 & 0.74 & 203 & 0.42 & 373 & 0.45 \\
\hline 30-39 & 314 & 0.43 & 635 & 0.47 & 262 & 0.78 & 258 & 0.60 & 681 & 0.51 \\
\hline $60-69$ & 1,006 & 0.64 & 1,358 & 0.58 & 1,317 & 0.90 & 1,315 & 0.74 & 1,694 & 0.72 \\
\hline $70-79$ & 1,136 & 0.63 & 1,420 & 0.62 & 1,563 & 0.93 & 1,547 & 0.80 & 1,342 & 0.75 \\
\hline $80-89$ & 1,224 & 0.65 & 1,147 & 0.64 & 1,446 & 0.93 & 1,432 & 0.82 & 1,008 & 0.77 \\
\hline 90-99 & 1,123 & 0.67 & 885 & 0.67 & 1,232 & 0.94 & 1,184 & 0.85 & 668 & 0.78 \\
\hline $100-199$ & 4,115 & 0.70 & 2,008 & 0.68 & 3,324 & 0.96 & 3,267 & 0.86 & 1,622 & 0.82 \\
\hline $200-499$ & 709 & 0.84 & 497 & 0.83 & 621 & 0.98 & 607 & 0.92 & 421 & 0.92 \\
\hline$>499$ & 828 & 0.95 & 687 & 0.95 & 761 & 0.99 & 745 & 0.98 & 619 & 0.98 \\
\hline
\end{tabular}

the fertility traits were unfavorably correlated with 3 yield traits (Table 5). For the 3 interval traits CF, FSh and FSc, EBV correlations with milk production EBV ranged from 0.14 between FSh and fat yield to 0.41 between DO and milk yield EBV. In comparison, lower EBV correlations were found between the nonreturn rate traits and the 3 yield traits, varying from -0.10 between $\mathrm{NRh}$ and fat yield to -0.25 between NRc and protein yield. Total conformation was weakly correlated with the fertility traits. Somatic cell scores were found to be favorably correlated with all the fertility traits, although at a lower level than the milk production traits. Moderate, favorable correlations existed between the EBV of the fertility traits and combined longevity, with greater correlations for the 3 intervals than the 2 nonreturn rate traits. The EBV correlations in Table 5 suggest that selection on fertility can contribute to improving the longevity of dairy cattle.

A fertility selection index was composed of the 5 fertility traits, with double weights on the cow fertility traits compared with the 2 heifer traits. Within heifers or cows the 2 fertility traits of heifer or 3 fertility traits of cows, respectively, were given equal weights. A conception index was set up in the same way as the fertility index, except the cow fertility trait $\mathrm{CF}$ was excluded.

Among animal scientists and breeders there has been a debate about the optimal definition of the cow fertility trait FSc interval from first to successful insemination. Some prefer the interval from first to last insemina-

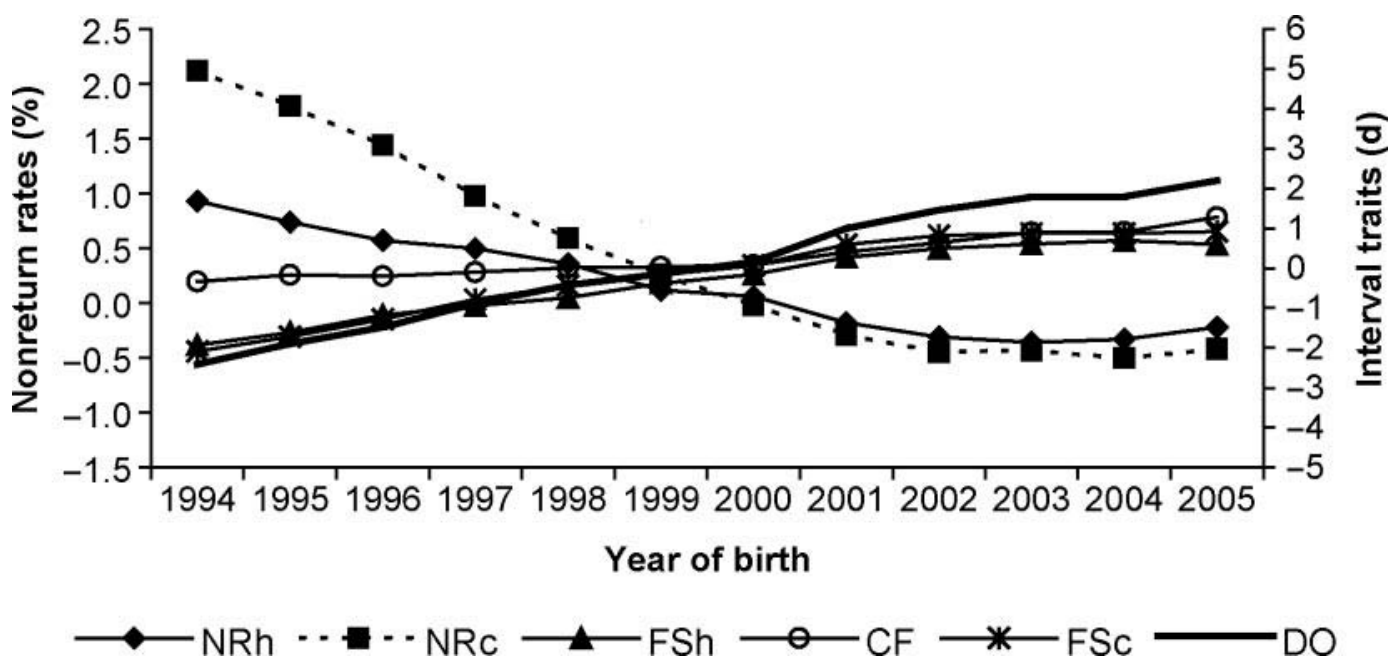

Figure 5. Genetic trends of heifer and cow fertility traits in German Holstein female animals with heifer and at least one cow insemination record. $\mathrm{NRh}$ and $\mathrm{NRc}=$ nonreturn rate of heifer and cow, respectively; FSh and FSc $=$ interval first to successful insemination of heifer and cow, respectively; $\mathrm{CF}=$ interval calving to first insemination; and $\mathrm{DO}=$ days open. 
Table 4. Correlations of female fertility daughter yield deviations with EBV by birth year for Black-and-White Holstein bulls that had at least 50 daughters for respective traits in a January 2008 genetic evaluation

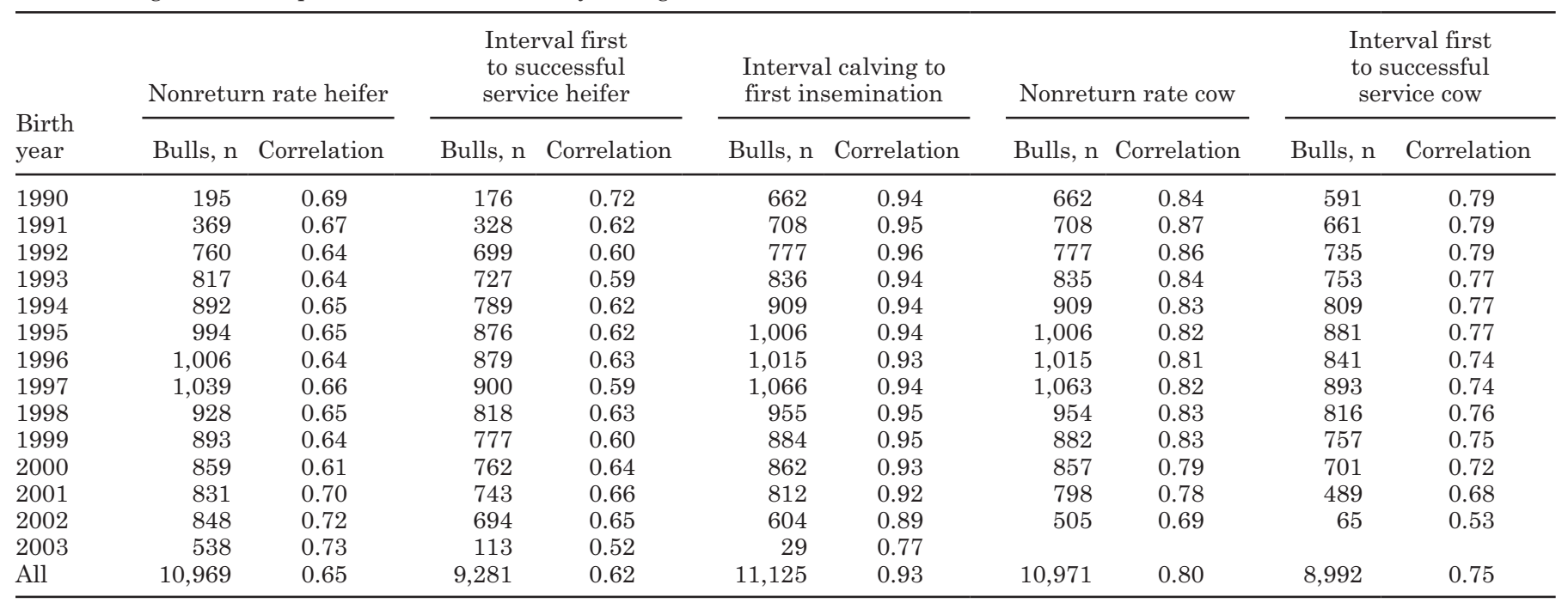

tion, because using the interval first to successful insemination, FSc, excludes cows that never conceive or are culled. The reason for choosing the definition FSc is that using the interval from first to last insemination can lead to unstable EBV over consecutive genetic evaluations for cows that have lactations in progress, because, for such cows, phenotypic value of the interval from first to last insemination would change between consecutive genetic evaluations. Although the incomplete insemination information is treated as a missing value until it is verified with the following calving, the multiple trait model can project EBV of this fertility trait reasonably well by optimally considering phenotypic information of this trait from previous lactations and the 2 correlated fertility traits CF and NRc from the same lactation of the same cow and her parental average of this fertility trait. However, our fertility model needs to be improved to consider insemination information of culled cows. In some countries, such as the Netherlands (de Jong, 2005), production traits are included in national fertility evaluations as correlated traits; the inclusion of the correlated production traits allows consideration of the selection in production traits on fertility EBV. Our fertility model does not take the correlated production traits into account, because the current international genetic evaluation is based on pure fertility information and cannot remove the influence of production traits on fertility proofs. Additionally, we will perform a 2-step multiple-trait genetic evaluation using yield deviations and EDC by including all relevant traits for setting up total merit index (e.g., production and fertility traits). The resulting fertility proofs from the multiple-trait models would contain correlated information from production and other traits.

\section{CONCLUSIONS}

A genetic evaluation system based on a multi-trait animal model was developed for 5 fertility traits of dairy cattle, nonreturn rates to $56 \mathrm{~d}$ of heifer and cow, interval from calving to first insemination, and interval from first to successful insemination of heifer and cow. Genetic parameters of the fertility traits were esti-

Table 5. Correlations of EBV of female fertility with other traits of Black-and-White Holstein bulls that had at least 50 daughters for respective traits in a January 2008 genetic evaluation

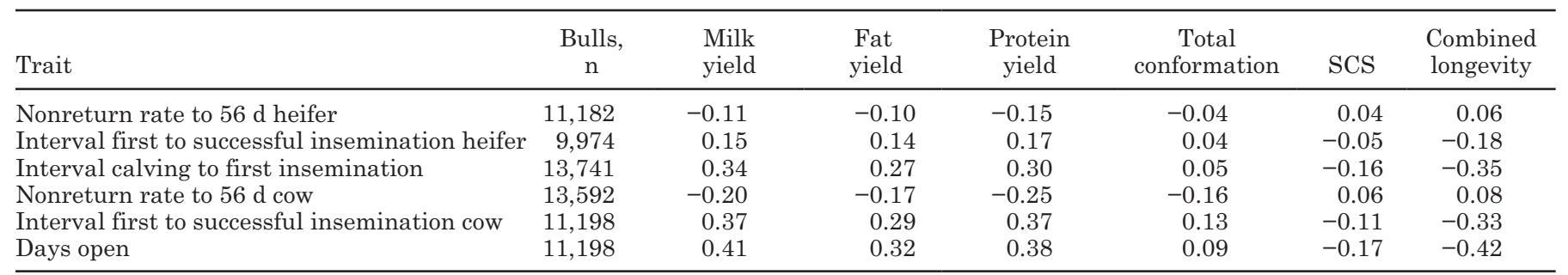


mated using the REML method. Heritability estimates were small for all the fertility traits, ranging from 1 to $4 \%$. A very large mixed model equation system was efficiently solved using PCG or Gauss-Seidel algorithm in cooperation with iteration on data technique. Reliability values of fertility EBV were approximated using the MTEDC approach. Average yield deviations of female animals and DYD of bulls were calculated following a multi-trait method. About 26 million insemination records of female animals of Holstein, Red dairy cattle, and Jersey from Germany, Austria, and Luxembourg were jointly analyzed using the newly developed fertility genetic evaluation software. Unfavorable genetic trends were found for all the fertility traits, with weaker trends for heifer traits than for cow traits. Considering the very low heritability values of the fertility traits, high correlations were obtained between DYD and EBV for bulls with a reasonable number of daughters, indicating a high consistency between DYD and EBV. Based on EBV correlations between the fertility and other traits, conclusions can be drawn that including fertility traits in selection index can halt the deterioration of fertility caused by correlated selection response of milk production and improve the longevity of dairy cattle.

\section{ACKNOWLEDGMENTS}

Two anonymous reviewers are greatly thanked for their valuable suggestions and comments, which improved this manuscript significantly.

\section{REFERENCES}

Berry, D. P., S. Coughlan, and R. D. Evans. 2007. Preliminary genetic evaluation of female fertility in Ireland. Interbull Bull. 37:125-128.

de Jong, G. 2005. Usage of predictors for fertility in the genetic evaluation, application in the Netherlands. Interbull Bull. 33:69-73.

Ducrocq, V., and T. Druet. 2003. Advances in computing strategies for the solution of huge mixed model equations. EAAP meeting. EAAP, Rome, Italy.
Fogh, A., A. Roth, O. Maagaard Pedersen, J.-Å. Eriksson, J. Juga, M. Toivonen, I. M. A. Ranberg, T. Steine, U. Sander Nielsen, and G. Pedersen Aamand. 2003. A joint Nordic model for fertility traits. Interbull Bull. 31:52-55.

Gredler, B., C. Fuerst, and J. Sölkner. 2007. Analysis of new fertility traits for the joint genetic evaluation in Austria and Germany. Interbull Bull. 37:152-155.

Jamrozik, J., J. Fatehi, G. J. Kistemaker, and L. R. Schaeffer. 2005. Estimates of genetic parameters for Canadian Holstein female reproduction traits. J. Dairy Sci. 88:2199-2208.

Jorjani, H. 2006. International genetic evaluation for female fertility traits. Interbull Bull. 35:42-46.

Kovač, M., E. Groeneveld, and L. A. García-Cortés. 2002. VCE-5, A package for the estimation of dispersion parameters. 7th World Congr. Genet. Appl. Livest. Prod., Montpellier, France. Commun. no. $28-06$

Lidauer, M., I. Strandén, E. A. Mäntysaari, J. Pösö, and A. Kettungen. 1999. Solving large test-day models by iteration on data and preconditioned conjugate gradient. J. Dairy Sci. 82:2788-2796.

Liu, Z., F. Reinhardt, A. Bünger, and R. Reents. 2004. Derivation and calculation of approximate reliabilities and daughter yielddeviations of a random regression test-day model for genetic evaluation of dairy cattle. J. Dairy Sci. 87:1896-1907.

Pasman, E., J. Jaitner, F. Reinhardt, and S. Rensing. 2006. Development of a new evaluation for sire and cow fertility. Interbull Bull. 34:34-37.

Szyda, J., Z. Liu, F. Reinhardt, and R. Reents. 2005. Estimation of quantitative trait loci parameters for milk production traits in German Holstein dairy cattle population. J. Dairy Sci. 88:356367.

Tarrés, J., Z. Liu, V. Ducrocq, F. Reinhardt, and R. Reents. 2007. Validation of an approximate REML algorithm for parameter estimation in a multitrait, multiple across-country evaluation model: A simulation study. J. Dairy Sci. 90:4846-4855.

Tarrés, J., Z. Liu, V. Ducrocq, F. Reinhardt, and R. Reents. 2007a. Parameter estimation of longevity and type traits from France and Germany with a single trait MACE model. Interbull Bull. 37:98-101.

van Doormaal, B. J., G. J. Kistemaker, and F. Miglior. 2007. Implementation of reproductive performance genetic evaluations in Canada. Interbull Bull. 37:129-133.

VanRaden, P. M., A. H. Sanders, M. E. Tooker, R. H. Miller, H. D. Norman, M. T. Kuhn, and G. W. Wiggans. 2004. Development of a national genetic evaluation for cow fertility. J. Dairy Sci. 87:2285-2292.

Wade, K. M., and R. L. Quaas. 1993. Solution to a system of equations involving a first-order autoregressive process. J. Dairy Sci. 76:3026-3032.

Wall, E., I. M. S. White, M. P. Coffey, and S. Brotherstone. 2005. The relationship between fertility, and selected type information in Holstein-Friesian cows. J. Dairy Sci. 88:1521-1528. 